\title{
Reflexões sobre uma experiência investigativa com a capoeira
}

\author{
Flávio Soares Alves* \\ Yara Maria de Carvalho*
}

\begin{abstract}
Resumo: O objetivo deste texto é descrever os movimentos de uma experiência investigativa com a capoeira. Tal descrição coloca em cena os desvios e transgressões que testemunham certa propensão ao devir do percurso metodológico. Buscase mapear as formas através das quais os procedimentos foram desconstruídos e transformados na pesquisa de campo. Pretende-se compreender como o envolvimento do pesquisador com o campo força os princípios regulamentares de ação a seus limites, mantendo a atitude investigativa na tensão entre a função referencial - que aponta para a aplicação regular dos procedimentos - e a propensão ao devir. Desta forma, evidencia-se a introdução do intensivo na relação investigativa e é o registro desse intensivo que alimenta esta descrição.
\end{abstract}

Palavras-chave: Métodos. Cartografia. Capoeira.

\section{INTRODUÇÃO}

Este texto assume uma posição reflexiva para apresentar e problematizar uma experiência investigativa com a capoeira. ${ }^{1} \mathrm{O}$ primeiro passo desta reflexão coloca em cena o objetivo da pesquisa: investigar as práticas de constituição/invenção do capoeirista. Para tanto, a proposta desta investigação foi se implicar junto à capoeira e experimentar os movimentos do pensamento forjados desta visibilidade implicada.

Durante a pesquisa de campo nos envolvemos com os seguintes grupos de capoeira: Grupo Capoeira Brasil em Botucatu; Grupo Amukenguê em Jaú; Grupo Projete Liberdade na USP de

\footnotetext{
* Departamento de Educação Física. Universidade Estadual Paulista (UNESP). Rio Claro, SP, Brasil. E-mail: flavio_salves@hotmail.com

** Escola de Educação Física e Esporte. Universidade de São Paulo (USP), São Paulo, SP, Brasil. E-mail: yaramc@usp.br

${ }^{1}$ Dados da referida pesquisa: ALVES, 2011.
} 
São Paulo; Escola de Capoeira Raiz de Angola em Piracicaba; Centro de Capoeira Angola Angoleiro Sim Sinhô; Associação de Capoeira Angola Senhor do Bonfim e Grupo Capoeira Ginga-Brasília em São Paulo.

Frente à definição dos sujeitos da pesquisa, abriu-se a possibilidade de se desenvolver os procedimentos e foi justamente neste momento que a propensão ao devir revelou seu traço intempestivo, ao introduzir na investigação o seguinte desafio: como fazer funcionar a observação participante, as entrevistas e os diários de pesquisa sem abrir mão de um exercício que se constrói nas relações e que vai além da aplicação regulamentar de procedimentos previamente instituídos?

O princípio da cartografia (DELEUZE; GUATTARI, 1995) ajustou a atitude investigativa, chamando o pesquisador para $\mathrm{O}$ desafio da pesquisa-intervenção. ${ }^{2}$ Para tanto, foi preciso ajustar o olhar: ao invés de instalá-lo sobre o sujeito, numa projeção descendente que o toma de assalto, ousamos inverter seu ângulo de divergência, dissolvendo o ponto de vista do observador - aquele supostamente neutro que sobrevoa o campo investigativo - para se abrir às intensidades das relações. No bojo deste jogo a investigação foi se desenhando e calibrando seu traço e singularidades.

\section{E COMEÇA O JOGO...}

hoje conheci mestre Ananias. [...] já corre à boca pequena que sou um pesquisador. [...] Antes que pudesse ajeitar a apresentação me levam ao encontro ao mestre. Levo em minha testa a alcunha: pesquisador.

A face negra do mestre me encara, seu olhar me fita de canto. [...] Sem disfarce, numa espontânea e

\footnotetext{
${ }^{2}$ Segundo Passos e Benevides de Barros, o desafio da pesquisa-intervenção "é o de realizar uma reversão do sentido tradicional de método - não mais um caminhar para alcançar metas pré-fixadas (metá-hódos), mas o primado do caminhar que traça, no percurso, suas metas" (2009, p. 17). Tal reversão dá visibilidade à composição de um plano comum entre pesquisador e pesquisados - o plano da experiência enquanto intervenção - em meio ao qual o exercício da pesquisa assegura "o protagonismo do objeto e a sua inclusão ativa no processo de produção do conhecimento" (KASTRUP; PASSOS, 2013, p. 270).
}

Movimento, Porto Alegre, v. 20, n. 3, p. 1111-1132, jul./set. de 2014. 
sisuda expressão de estranhamento, olha para Minhoca e o interpela: "Quem é o sujeito?" Sintome um extraterrestre. [...] o momento é de se desatar os nós e Minhoca me ajuda nesta tarefa: “- É o Flávio, mestre”. [...] Recupero o fôlego... Mestre Ananias, no entanto, não perde tempo, se adianta para dentro do salão me deixando para trás. Alcança um banco e por ali se ajeita. [...].

Ajeito-me a seu lado... O mestre me interpela: "você é capoeirista?" Respondo ainda vacilante: "sim, vim pra cá conhecer o senhor e todo pessoal por aqui." Ainda desconfiado, vai direto ao ponto que the incomoda: "veio aqui fazer pesquisa é?" E respondo: "nada mestre, vim vadiar com vocês!" Sinto a coragem reavivar minhas veias, mas a reação do mestre mostra que ele nem mesmo escutou minha resposta. Logo desata um resmungar desaforado: "não sei pra que serve estas pesquisas aí... o que fazem com isto? Serve pra quê? Não tem coisa melhor pra fazer?" Curiosamente, não entro na onda da provocação, pelo contrário, dissimulo, desconverso... [...] $\mathrm{O}$ mestre começa a me perguntar sobre minha história com a capoeira. Quando digo que já passei por vários mestres devido às várias mudanças de cidade que realizei na minha vida, por conta dos estudos que realizei, o mestre se adianta indignado: "passou por vários mestres, é? Isto não presta não!", e desata uma conversa embromada que escapa de meu entendimento: não entendi uma só palavra.

Daquele ponto ambos ficam mais relaxados. O desatar da conversa foi dissolvendo os nós... [...]. (ALVES, 2011, p.40-41).

A estrutura textual acima se concentrou na apreensão das relações em ato no desatar do encontro, expondo os modos como o encontro com o mestre foi sendo estabelecido na ordem do acontecimento. Não havia ali, em meio às relações, procedimentos prévios a serem contemplados, mas apenas problemas e casos de solução surgindo um após o outro, como acontecimentos reais.

Movimento, Porto Alegre, v. 20, n. 3, p. 1111-1132, jul./set. de 2014. 
Para dar prosseguimento às relações ali estabelecidas, foi preciso se envolver e ser envolvido pelo encontro com o mestre, criando, assim, um campo, em meio ao qual o encontro se estruturou. Com isso, as relações foram se seguindo, tecendo a trama dos problemas e dos casos de resolução observados na própria constituição do encontro. ${ }^{3}$

O escritor que se enuncia no texto nega a posição de oposição, ou de neutralidade no diálogo, para se abrir ao encontro com o outro e achar aí os problemas, no rastro das singularidades que só emergem nos envolvimentos da pesquisa de campo.

Como desdobramento dessa atitude, a pesquisa se engendra como exercício de aprendizagem. Deleuze ajuda-nos a sustentar essa ideia, quando salienta que aprender é constituir espaços de encontro, nos quais se aninham "atos vivos", que arrancam o pensamento de seu ponto de estacionamento - onde reina a imagem de um pensamento que pressupõe a si mesmo - forçando-o a pensar (DELEUZE, 2006, p.213).

\footnotetext{
${ }^{3}$ Os excertos grifados no fragmento de diário acima podem ser citados como exemplos de como o pesquisador foi se deixando afetar por esse campo de envolvimentos estabelecido no encontro com o mestre. No primeiro excerto, quando o pesquisador responde à pergunta do mestre sobre suas intenções de pesquisa, aparece o termo "vadiar". A ação de "vadiar" move o mergulho do pesquisador no território existencial da capoeira. Neste sentido a intenção do pesquisador com essa resposta foi romper com a tendência implícita na pergunta do mestre em reafirmar a oposição e assimetria entre os interlocutores, na busca por outras relações constituídas a partir da ação de vadiar. É Alvarez quem nos dá essa pista ao afirmar que "cartografar é habitar um território existencial" (2007, p. 131), algo só possível na capoeira quando o pesquisador se permite dispor de um tempo com a capoeira na experiência da vadiação. A resposta do pesquisador, portanto, não funciona como estratégia de adiamento da revelação do pesquisador enquanto tal no território que se propõe estudar, mas, ao contrário, funciona como estratégia de dissolução da oposição entre as partes para a promoção de um plano comum (plano de forças), em meio ao qual, a habitação do pesquisador no território no qual se implica se engendra. A vadiação, portanto, é uma atitude que convida as partes à aventura do movimento, isto é, à experimentação das forças que se constituem na transversalidade, no exercício de "estar com". Do mesmo modo funciona o excerto seguinte em grifo. Segundo ALVES (2011), a malícia e a dissimulação são atitudes que fazem parte do exercício da vadiação. Dessa forma, ao dissimular e desconversar, em resposta à provocação do mestre, o pesquisador introduz na conversa forças que ajudam na intensificação do encontro. Segundo Alvarez essa intensificação, própria do tempo da vadiação, deixa à mostra a "ética da mandinga" (2007, p. 21), na qual se encontra em movimento a tradição viva da capoeira, algo possível através da vivência dos ritos, nas expressões estéticas, nos ritmos, na magia, nos aspectos políticos de resistência e negociação com o adversário, na dimensão coletiva, nos diálogos entre os capoeiristas, na roda de capoeira e no papel do mestre de capoeira.
} 
Mediante essa mobilização do pensamento, o aprender só deixa passar aquilo que lhe afeta nos domínios da sensibilidade. ${ }^{4}$ Tais domínios não admitem metas predeterminadas, portanto o pesquisador que ousa ser movido por esste exercício do aprender não visualiza mais uma meta prévia - alvo sobre o qual lança sua investigação - mas permanece atento ao desconhecido, construindo seu caminho a cada passo, na direção da habitação do território que quer conhecer.

Como efeito desse deslocamento do olhar, a noção de rigor se modifica: deixa de se associar à noção de exatidão e precisão, para expressar compromisso e interesse (PASSOS et al., 2009). No campo onde esse compromisso e interesse se movimentam, a investigação trilha seus rumos. Como desdobramento o pesquisador aprende, e no curso desse aprendizado, faz pesquisa.

Fazer parte, colocar-se junto à experiência, e nela intervir. Eis o exercício através do qual a investigação se abriu à recepção dos afetos. Era preciso cultivar uma disponibilidade à experiência. Alvarez (2007) já tinha alertado sobre essa necessidade. A disponibilidade demanda tempo, interesse e implicação junto à capoeira. Era preciso, portanto, se esgueirar no insondável de um exercício no qual, ao invés da pesquisa sobre alguém se pretende pesquisar com alguém. Assim, atentos a um "pesquisar com", mobilizamo-nos ao múltiplo, através do tempo da vadiação.

\section{TEMPO DA VADIAÇÃO E O CONVITE À RODA}

O tempo da vadiação é aquele que ousa se esquivar do tempo cronológico, seguindo os rastros de um espaço-tempo dinâmico em processo na vivência junto à capoeira (ALVES, 2011; ALVAREZ, 2007). Imerso no tempo da vadiação, o pesquisador se posiciona como aprendiz, e, como tal, se deixa encharcar pelas intensidades

\footnotetext{
${ }^{4}$ Trata-se aqui de um exercício transcendente, no qual a sensibilidade se vê livre das coerções da consciência e impulsionada pela imaginação se aventura no pensamento involuntário, no qual só "o fortuito ou a contingência do encontro garante a necessidade daquilo que ela [a sensibilidade] força a pensar" (DELEUZE, 2006, p.211).
}

Movimento, Porto Alegre, v. 20, n. 3, p. 1111-1132, jul./set. de 2014. 
que por aí atravessam. E essas intensidades ensinam muito sobre a capoeira, mas condicionam esse ensino à emergência de uma experiência que não pode ser antecipada, ou controlada e que, portanto, reclama por cultivo e disposição de um "perder tempo" junto à prática da capoeira.

Tal verificação corrobora os estudos de Alvarez (2007). Segundo este autor, não é possível treinar a vadiação. Só a convivência solta do capoeirista em seu território existencial a evoca, o que releva seu caráter espontâneo. A vadiagem forja um espaço de intimidade, no qual os participantes se veem às voltas com a capoeira. Atentos a este espaço de intimidade, aceitamos o desafio da vadiação e assim experimentamos a capoeira abertos a uma atenção flutuante e a uma disposição tateante e aventureira, em meio à qual a experiência vivida se deixou afetar pela capoeira que ali consistia. Como efeito dessa abertura aos afetos, a pesquisa foi sendo forjada como movimento de uma visibilidade imersa no território estudado.

Outra prática é chamada à pauta para ajudar na constituição da visibilidade implicada. Trata-se da roda de capoeira, na qual o efeito de contágio e de provocação, forjados na vadiação, reclama por um exercício mais intenso avesso à neutralidade de um pesquisador que se recolhe à observação passiva. A coragem para aceitar o convite da roda de capoeira é o primeiro passo, no entanto, é preciso ir além das palavras! Assim, aceitando o convite à roda e ao jogo da capoeira o pesquisador se assume como aprendiz aberto ao trânsito dos afetos que por ali cruzam. Para tanto, o pesquisador/ participante da roda esteve atento às palavras de Passos e Eirado:

[o pesquisador] não pode estar localizado na posição de observador distante, nem pode localizar seu objeto como coisa idêntica a si mesma. $\mathrm{O}$ cartógrafo lança-se na experiência, não estando imune a ela. Acompanha os processos de emergência, cuidando do que advém. É pela dissolvência do ponto de vista que ele guia sua ação (PASSOS et al., 2009, p.129).

Movimento, Porto Alegre, v. 20, n. 3, p. 1111-1132, jul./set. de 2014. 
Reflexões sobre uma experiência investigativa ...

E, assim, inscreveu-se nesta dissolução a possibilidade da escrita...

\section{A RODA DE CAPOEIRA E A ESCRITA}

A roda de capoeira convidou-nos a ancorar na experiência vivida. Lá, imerso nela, a sensibilidade aflorou: desatou-se no cingir atravessado de um frio na barriga, no brotar furtivo da valentia, na densidade quase tátil da provocação. Enfim, em meio à inscrição desses afetos, abrimo-nos à roda de capoeira e, implicados, permitimo-nos acompanhar o que por ali se passava, tateando, com curiosidade, a experiência performativa que nos acometia.

Segundo Deleuze e Guattari (1995, p.14-17), na experiência performativa há uma coemergência entre pesquisador, sujeito e realidade estudada. Em meio a essa coemergência, cruzam-se as forças que tornam possível a emergência dessa experiência na realidade.

No espaço ritual da roda de capoeira a experiência performativa é alcançada quando a dualidade dos atores que a compõe é dissolvida em função da emergência de uma realidade onde só existem forças em intenso cruzamento. No plano onde essas forças se evidenciam, surge a impressão dos afetos. A emergência desses afetos não recolhe as impressões dentro de um plano pessoal, que sustenta o registro regular da identidade. Quando implicado, diria Deleuze, o sujeito unificado, senhor de si, está ausente e no lugar dele age um sujeito larvar, único capaz "de suportar os traçados, os deslizamentos e rotações" que se movem em meio à experiência intensiva (2006, p.308). Tal sujeito larvar só desponta na experiência performativa quando descobre um espaço e um tempo dinâmicos - os chamados "dinamismos espaciotemporais" - onde:

[...] só se cavam espaços, só se precipitam ou desaceleram tempos à custa de torções e deslocamentos que mobilizam e comprometem todo o corpo. Pontos brilhantes nos atravessam, singularidades nos arrepiam... (DELEUZE, 2006, p.308).

Movimento, Porto Alegre, v. 20, n. 3, p. 1111-1132, jul./set. de 2014. 
A roda de capoeira, e o exercício da vadiação, foram os momentos através dos quais tocamos a dinâmica furtiva, que localiza e dá ânimo ao sujeito larvar. A escrita dos diários serviu-se dessa dinâmica furtiva para traçar seu traço, para tanto, teve que estar lá ancorada: na roda e na vadiação.

Através dos diários foi possível reunir informações objetivas e impressões furtivas. Assim o relato se manteve atento à descrição daquilo que se deu no plano das forças, lançando o pesquisador novamente para dentro da roda de capoeira ancorando aí a regência da escrita. Nos relatos, inscrevemos aquilo que julgamos importante, mas à medida que nos deixamos levar por um movimento espontâneo de explicitação ${ }^{5}$ das experiências vividas inscrevemos também algo mais precioso: dados que permaneciam até então num nível inconsciente e pré-refletido.

Segundo Barros e Kastrup (2009, p.69-70), o alcance de dados como esses não se faz sem certo recolhimento, "cujo objetivo é possibilitar um retorno à experiência do campo, para que se possa então falar de dentro da experiência e não de fora, ou seja, sobre a experiência".

O relato, portanto, não se fez sem uma tomada de fôlego, que nos reporta para o campo intensivo das forças, onde nos encharcamos dos afetos em meio ao curso dos acontecimentos. Antes da escrita, portanto, tivemos que nos abrir aos diversos pontos de vista que habitavam uma mesma experiência de realidade e, nessa abertura, deixamo-nos afetar sem apego por seus movimentos. Assim, nos rastros de uma visibilidade implicada a figura do pesquisador como observador externo e neutro foi sendo dissolvida.

\section{A DISSOLUÇÃO DO PONTO DE VISTA DO OBSERVADOR}

Vejo os corpos em minha frente desatando
um jogo corporal malicioso, circular, espiral.
Concentro o olhar entre os oponentes. Firmo o

${ }_{5}^{5}$ Segundo Kastrup e Barros $(2009$, p.83), explicitação designa "o ato de trazer à consciência uma dimensão pré-reflexiva da ação".

Movimento, Porto Alegre, v. 20, n. 3, p. 1111-1132, jul./set. de 2014. 
foco... insisto no foco até que o desfoco.... e a imagem se perturba. Mantenho a firmeza do olhar como que sintonizando outro canal perceptivo por sobre a imagem em minha frente. Não vejo mais detalhes, vejo só borrões em movimento... corpos... e o chão e o espaço entre os corpos... (ALVES, 2011, p.50).

Um primeiro olhar sobre este diário remete o leitor à ótica de um ponto de vista, em que uma identidade individualizada se permitiu a expressão do caso relatado. Todavia, os verbos conjugados na primeira pessoa do singular não concorrem a favor do contorno de uma autoria, mas, antes, à sua dispersão, ao operar o traço de uma escrita forjada num campo problemático. Como isso foi possível?

Ao "ver", “concentrar", "firmar", “insistir", “manter”, o escritor "viajou", ou seja, se permitiu escrever num nível perceptivo onde só existem "corpos... e o chão... e o espaço entre os corpos", isto é: relações em ato. Os verbos problematizam, isto é, criam um itinerário da observação que se orienta na direção de num espaçotempo dinâmico, em torno do qual a percepção do escritor "viaja" para outros níveis, onde vigora a presença dionisíaca do sujeito larvar.

A escrita transborda para além das bordas da autoria, abrindo passagem aos múltiplos pontos de vista que habitam uma mesma realidade estudada. Assim, ao se colocar junto à capoeira, o pesquisador habita também essa realidade e nela intervém. Como efeito, o ponto de vista do observador é dissolvido. À escritura resta o registro daquilo que insiste no caso estudado, como movimento, isto é, força de criação.

Convém salientar que não se deve confundir dissolução do ponto de vista do observador com anulação da observação. A dissolução implica na desmontagem dos juízos de valor e da vigência linear e monótona da consciência. A solvência desses juízos eleva a intervenção para um plano coletivo, onde, como diria Guattari (2004), transita uma rede de comunicações transversais

Movimento, Porto Alegre, v. 20, n. 3, p. 1111-1132, jul./set. de 2014. 
que atravessam o pesquisador em seu ato investigativo, atando produção de conhecimento e produção de realidade.

Nesse sentido, a regência em primeira pessoa na escrita dos diários, antes de enunciar a identidade individualizada do pesquisador, coloca em cena a expressão de um "eu" dissolvido, aberto ao encontro furtivo com outros pontos de vista. Segundo Lourau (1998), a experiência da escrita sob os domínios dessa dissolução tira do texto o excesso de pessoalidade, permitindo que o autor possa compor o sentido em um plano coletivo, onde experimenta o limite da consciência de si. Nessa dissolução, a escrita é operada em uma espécie de transe.

A experiência da roda de capoeira ofereceu um caminho através do qual foi possível alcançar este transe. Lá, em ato, o escritor foi mobilizado, ou seja, esteve longe da acomodação de um lugar. Assim, implicado, fez da escrita uma experiência que já não era mais sua, pois foi tecida na fronteira, nos limites de um si fora de si que aponta para o espaço da experiência (SOUZA, 2008).

\section{O JOGO E A CONVERSA: A CAPOEIRA NA INSCRITA FURTIVA DO INSTANTE}

às vezes as pessoas olham e acham que a capoeira é uma coisa combinada, e não é bem assim. É algo de momento. [...] A capoeira é livre, ela é liberta pra você poder na hora da roda criar qualquer outro tipo de movimento, [...] é lógico, a gente treina pra poder fazer, mas na roda [...] é aquilo que seu espírito sentir, que seu coração... e você vai, e joga, e faz (ALVES, 2011, entrevista realizada em 31/10/2008).

Esta fala de contramestre Buda nos coloca às voltas com o plano das sensações, pois enfatiza que a performance na capoeira se passa num outro nível perceptivo, no qual as habilidades treinadas são extraídas da memória que as acomoda para mobilizar o plano de forças onde acontece o jogo de capoeira. Da mesma forma queremos olhar para o diálogo verbal.

Movimento, Porto Alegre, v. 20, n. 3, p. 1111-1132, jul./set. de 2014. 
Assim pontua mestre Brasília:

[no jogo de capoeira] você tem que perceber... é como eu conversando aqui com você, aí você me falou: "Puxa, mas você falou algo interessante aí", aí você guardou isto e aí você repete... o jogo é a mesma coisa... eu tô fazendo um movimento e "pá"! Eu fiz um movimento e aí você veio e [pensou:] "é aqui que eu vou pegar ele", aí eu repito o movimento e se você vier eu entro [e te pego]! Entendeu? Isto é jogar capoeira, entendeu? (ALVES, 2011, entrevista realizada em 02/12/2008).

A relação entre as partes desbrava os rumos da conversa, e, na construção desses rumos, se desata certo fluxo. Atentos a esse fluxo lançamo-nos à produção das entrevistas. Tal produção não serviu como mero momento de coleta de informações, mas como espaço de interação, no qual pesquisador e sujeito mergulharam juntos para tecer as tramas daquilo que foi dito.

Soa estranho pensar em entrevistas no âmbito das ciências, sem pensar em sua função catalisadora, afinal, a busca pelo sujeito de pesquisa só parece se justificar se dele o pesquisador quiser extrair alguma informação. De qualquer modo as informações vêm, é claro, mas a coleta dessas informações permitiu a aproximação com o entrevistado, gerando espécie de contágio entre as partes. A entrevista realizada com mestre Ananias mostra como o pesquisador e o grupo se esgueiraram nas tramas desse contágio:

Mestre Ananias: [...] neste mundo, se não tiver conhecimento, meu filho, tá frito! Tá frito mesmo! Porque o negócio não é chegar dentro da roda da capoeira e estender a perninha... todo mundo sabe estender a perninha, mas entender que é bom, é preciso de muito batente...

Entrevistador: E o que eu tenho que fazer para entender?

Mestre Ananias: Precisa procurar seguir!! Seguir o regulamento do mestre... olha bem o que o mestre fala, olha o jeito que o mestre faz e explica

Movimento, Porto Alegre, v. 20, n. 3, p. 1111-1132, jul./set. de 2014. 
tudo... tem que se guiar pelo mestre. Hoje existe um monte de mestre de capoeira por aí.... tá cheio de mestre de capoeira boboca por aí. Eu não troco meus alunos por nada! [enfático] Meus alunos não têm diploma não. [...]

Aluno I: É que a gente já nasceu diplomado, mestre. [risos]

Mestre Ananias: É, deve ser... mas hoje em dia tem que tá no papel... Você não foi pra escola pra aprender? Você não sentou um pouco no banco da ciência? Se você não tivesse sentado um pouco no banco da ciência, hoje em dia você seria um burro!

Aluno II: No banco da ciência, mestre? [sem entender o que o mestre quis dizer]

Mestre Ananias: O banco da ciência é a escola. Onde mais você poderia ter tido um pouco mais de inteligência?

Aluno II: Mas mestre, meu diploma é de rua mesmo.

Mestre Ananias: Há quantos anos você está comigo? [pergunta direcionada ao aluno]

Aluno III: Faz uns aninhos já...

Mestre Ananias: E este daí que saiu daqui agora mesmo, quantos anos que ele está comigo?

Aluno III: Faz uns 15 anos.

Mestre Ananias: E não aprendeu nada! Tá desaprendendo tudo que aprendeu.

Entrevistador: Quem daqui está há mais tempo com o mestre Ananias?

Mestre Ananias: Ele aqui [aponta para o professor Minhoca]. Ele, o Rafaelzão...

Entrevistador: E o que estes alunos precisam saber para serem bons mestres futuramente? 
Mestre Ananias: Eles seriam como se fossem mestres já, porque tem capacidade para serem como mestres. Este aqui principalmente [aponta para o professor Minhoca]... e eu não troco os meus alunos por mestre nenhum... (ALVES, 2011, entrevista realizada em 31/08/2009).

O que interessa considerar aqui são os rastros do contágio. Nesse intento, cabe observar a quantidade de interlocutores: são cinco (o que caracteriza uma entrevista realizada em grupo). As trocas de turno da fala cruzam-se no espaço da interação. As ideias dobram-se umas sobre as outras, movidas pela curiosidade. Enquanto isso, o pesquisador acompanha a conversa. Dessa forma, o olhar que vai e volta entre os turnos da fala se deixa contagiar por aquele encaminhamento espontâneo. Tal constatação corrobora as ideias de Tedesco, Sade e Caliman. Segundo estes autores, "a entrevista acompanha o movimento e, mais especificamente, os instantes de ruptura, os movimentos de mudança presentes nas falas." (2013, p. 300).

Qual era mesmo a questão de partida na conversa? Não importa mais. O contágio a dissolveu. Se havia um saber suposto foi despojado na implicação junto ao grupo. Na ocasião desta entrevista, registramos impressões sobre o exercício de implicação grupal assim constituído:

[...] a palavra "entrevista" incomodava. [...] Frente à vivência [...] a possibilidade de uma entrevista parecia não apresentar valor verossímil. [...] Todavia, os receios foram sendo diluídos com o tempo e com a disposição para o diálogo.

Colocar-se na conversa, sem pensar muito nela e nos seus propósitos previamente planificados, foi um exercício de libertação.

A direção das perguntas era totalmente imprevista e seguia os encaminhamentos dados em meio ao curso da conversa. Por várias vezes em meio à interação, houve uma inversão de papéis e o entrevistador se tornou ouvinte, pois na medida em que o mestre falava, os alunos se sentiam

Movimento, Porto Alegre, v. 20, n. 3, p. 1111-1132, jul./set. de 2014. 
motivados para perguntar e saber mais sobre a capoeira e sobre o próprio mestre. [...] Foi na trilha deste diálogo que a entrevista foi sendo constituída (ALVES, 2011, p.56-57).

Assim, sacudido no trânsito das relações em ato, a oposição assimétrica entre as partes foi sendo dissolvida, forjando uma coemergência do discurso. O jogo instalado na interação foi se intensificando de modo a mover os interlocutores da relação de oposição que os localizava. Assim, já não havia oponentes, já não havia entrevista, mas somente forças em relação. A entrevista, então, acontece como um diálogo (TEDESCO; SADE; CALIMAN, 2013).

Como isso foi possível? O leitor espera que se desdobre aqui uma lista protocolar que esclareça os procedimentos através dos quais essa elevação ao plano das forças foi possível. Muito pode ser dito, mas, seja o que for, o procedimento alinhado à luz da consciência onde o plano das formas se engendra - se dissolve no ato em que a interação se constitui. Dessa forma, no ir e vir das falas, as respostas gingam com as perguntas e a conversa transcorre intensiva.

Frente à eminência da dissolução de um procedimento prévio posto em ato, as palavras de mestre Zequinha parecem ter mais a dizer:

a gente precisa fazer a capoeira acontecer, então pra isto às vezes você precisa diluir algum conflito, começar relaxado, deixando o outro gingar, vendo as respostas do cara e por aí vendo como a coisa acontece... (ALVES, 2011, entrevista realizada em 20/03/2009).

A ginga mobiliza o diálogo, mas como gingar? Deixando vir o que vier.

\section{A DISSOLUÇÃO DO ROTEIRO DE ENTREVISTA}

$\mathrm{Na}$ ocasião do projeto de pesquisa foi produzido um roteiro de entrevista. A formulação do roteiro levou em consideração o 
seguinte questionamento: como o sujeito vai inscrevendo para si um estilo capoeira de ser ao se envolver e ser envolvido pela capoeira?

O roteiro deu o tom da interlocução, mas, a partir dele, outros tons se sucederam, dando curso ao improviso - inscrito nas palavras de fuga - mas também, ao traço performático da autoria, expresso pelas palavras de ordem. ${ }^{6}$ Assim, em meio aos improvisos, vemonos perdidos nos descaminhos da fala: vulnerável ao encontro com o outro. Há uma injunção aqui, afinal, quando se fala em entrevistas se supõe a aplicação de um método. Assim, nem de longe podemos nos reconhecer perdidos, ainda mais quando estamos em meio à pesquisa de campo. A definição dos procedimentos não pode deixar margem à dúvida. E se não há dúvida, não se dá chance aos elementos que desviam o olhar do pesquisador da trilha da evidência. Não obstante, as entrevistas realizadas se perderam no desatar das falas.

As palavras de ordem elaboradas no roteiro da entrevista deram um direcionamento inicial à interlocução, mas à medida que os interlocutores se envolveram a entrevista foi se elevando para o plano das forças. Para que essa elevação fosse possível, provocamos o interlocutor para contagiá-lo com aquele espaço de interação. O simples fato de colocar a escuta à disposição dos capoeiristas já os mobilizava à fala solta e generosa sobre suas vidas junto à prática da capoeira. Segundo Lourau (1996), esse movimento provocativo é o que permite a emergência da dinâmica instituinte que ata os interlocutores no espaço de implicação.

Nos domínios desse espaço de implicação, o exercício de controle se sustentou de modo paradoxal: se constituiu a partir das

\footnotetext{
${ }^{6} \mathrm{O}$ autor que enuncia o ato performativo quer fazer valer seu poder de enunciação, para tanto, faz uso de palavras de ordem, com as quais firma sua autoria. As palavras de ordem, segundo Deleuze e Guattari (1995b, p.16-17) aprisionam a realidade em um sentido dado. A experiência performativa é edificada pelas palavras de ordem, todavia, por entre suas estruturas porosas e solventes atravessam palavras de fuga, como movimentos que abrem caminho para a emergência de novas realidades. A abertura às palavras de fuga permite amainar o traço fálico da autoria, impedindo a tendência à sobreimplicação, onde o pesquisador reclama por uma verdade por ele revelada.
}

Movimento, Porto Alegre, v. 20, n. 3, p. 1111-1132, jul./set. de 2014. 
palavras de ordem registradas no roteiro, mas também pela ação original daquele que respondia segundo suas próprias motivações, dando à conversa rumos que se desdobravam como um hipertexto.

Visto dessa forma, foi possível verificar que uma resposta não estava necessariamente subordinada à pergunta antecedente - como efeito causal dela - mas se mostrava como expressão episódica emergente no momento da fala. A pergunta do interlocutor serviu, muitas vezes, como estímulo para a emergência de uma expressão latente e pré-refletida que desmontou o controle implícito na pergunta, dando à conversa um direcionamento imprevisível.

Observe como o diálogo com mestre Plínio foi se desdobrando, seguindo o curso da fala em interação:

Entrevistador: Eu gostaria de falar um pouquinho contigo sobre capoeira... você fique à vontade aí pra falar o que quiser... primeiro fala pra mim: qual o significado que a capoeira tem pra você? $\mathrm{O}$ que é a capoeira pra você?

Mestre Plínio: Humm... estas perguntas mais diretas e mais simples são as mais difíceis de responder, né?

Entrevistador: É, a capoeira parecer ser tão "da gente mesmo" que não tem nem o que falar, né! [risos].

Mestre Plínio: É [pausa] é porque, capoeira, pra mim é o [pausa] é a estrutura, é a base nesta minha vida toda. [...] eu estou todo dia na capoeira, então a capoeira seria uma mola mestra da minha vida, seria a razão do meu viver, é meu sustento, é a minha religião, é a minha ginástica, é a forma que eu encontrei de me encontrar comigo mesmo... A capoeira é a ligação entre meu interior e meu exterior... (ALVES, 2011, entrevista realizada em 26/03/2009).

Num primeiro momento, fica evidente que a resposta do mestre extrapola os limites implícitos pela questão: “o que é a 
capoeira pra você?". Logo na primeira réplica o interlocutor expõe o descabimento da questão a ele direcionada como quem diz: "é possível reduzir uma prática da existência dentro dos moldes objetivos desta simples e direta interrogativa?" Há aqui, portanto, uma sutil perda de controle sobre a intenção implícita na questão de partida, que mobiliza o interlocutor a uma resposta que se desdobra como um problema.

O entrevistador, no entanto, logo percebe a perturbação do entrevistado e se esquiva, adiantando-se aos movimentos do outro: "a capoeira parecer ser tão - da gente mesmo - que não tem nem o que falar né!" Tal esquiva soa como uma indução que supostamente conduz o entrevistado a uma lógica sobre ele imposta.

A reação seguinte do interlocutor é aceitar essa indução e ir junto com ela, respondendo: "É [pausa] é porque, capoeira, pra mim é o [pausa]...”. Esta afirmativa, no entanto, não sustenta aquela indução, pois a resposta indica a irredutibilidade de um sujeito que não se contenta simplesmente em afirmar ou negar, pois, se assim fosse, o interlocutor teria se satisfeito com a expressão "É". O que se viu, no entanto, foi uma reação/criação à suposta indução. As pausas - entremeadas por titubeios da fala - deixam à mostra um tempo de organização das ideias, onde o interlocutor se viu instigado a criar seu dizer, segundo suas próprias motivações.

Quando se libera acesso a esse movimento de criação a conversa se intensifica e a própria indução acaba funcionando como elemento de provocação que alimenta o traço sinuoso do jogo. Como diz mestre Plínio: "o bom jogo é quando um tá tentando pegar e o outro não está deixando" (ALVES, 2011, entrevista realizada em 26/03/2009). A indução, portanto, é elemento que faz parte da boa conversa, afinal, um jogador só "pega" o outro se tentar trazê-lo para seu jogo, induzindo-o aos seus domínios. O outro, no entanto, como bom jogador, se esquiva e não se deixa ser pego, tapeando a indução suposta. A pergunta, portanto, não controla necessariamente o que é dito, e nem poderia, pois a resposta foge do controle do entrevistador, afinal, não vem dele, mas de seu

Movimento, Porto Alegre, v. 20, n. 3, p. 1111-1132, jul./set. de 2014. 
interlocutor. $^{7}$ Assim a conversa se propaga, contagiando as partes e produzindo o footing da conversa. Segundo Goffman, footing é o enquadre, o clima de uma conversa e representa a "projeção do eu de um participante na sua relação com o outro, consigo próprio e com o discurso em construção" (2002b, p.107). Essa projeção pode ser negociada, ratificada, mantida, cos-sustentada, ou modificada a depender dos rumos desencadeados pelos interlocutores. Os acontecimentos que se desdobram no footing estão porvir na dinâmica relacional. Dessa forma, a conversa flui ao sabor das forças que se propagam, entrelaçando os interlocutores em um campo implicacional (LOURAU, 1993; GOFFMAN, 2002b).

Quem falou? Quem disse? Já não importam estas questões, visto que as entrevistas permitiram o acesso a um plano comunicacional, no qual os autores deslocaram o foco de seus próprios pontos de vista, liberando acesso a outros olhares. A atenção a um dizer constituído nesses atravessamentos deslocou o foco da entrevista, forjando o discurso co-autoral. Para dar visibilidade a este discurso, esse texto deixou se encharcar pelos movimentos da pesquisa, assim mapeamos o itinerário e o alcance dos procedimentos constituídos em campo.

\section{Considerações Finais}

Ao descrever a constituição dos procedimentos buscamos pelos movimentos que impediram a aplicação regular do método, forçando sua reinvenção. Desta forma, foi possível compreender que a constituição dos procedimentos pode ser também um exercício criativo que não abandona a função referencial dos procedimentos, mas que se serve das condições da experiência para forjar sua real medida.

\footnotetext{
${ }^{7} \mathrm{~A}$ pretensão do controle da conversa se sustenta na intenção implícita na pergunta - onde se inscrevem as palavras de ordem. Ao dar uma forma interrogativa a algo que acossa, o interlocutor quer saber algo. A preocupação aqui, neste algo a saber, não é com a suposta indução aí implícita, mas com a necessidade de deixar que o desatar da fala crie seus próprios rumos, amenizando as certezas do pesquisador, em função de um tateamento cego que faz com que os interlocutores explorem a conversa como quem explora cheio de curiosidade o desconhecido (DELEUZE; GUATTARI 1995a)
}

Movimento, Porto Alegre, v. 20, n. 3, p. 1111-1132, jul./set. de 2014. 
A preocupação com a síntese do processo, tão avidamente requerida na pesquisa positivista, tende a resumir a singularidade das investigações, dando-lhes um enquadramento regular. Definitivamente, não foi desse modo que operamos. Lá, em meio à experiência, o planejamento foi posto em prática, transformando-o em cultivo junto à capoeira. No curso desse cultivo os procedimentos foram sendo constituídos, forjando os traços de transformação e invenção da pesquisa.

O que emergiu lá em meio à experiência se desdobra aqui não para ditar novos parâmetros de controle e determinação da pesquisa de campo, mas para chamar a atenção para um princípio totalmente outro, movido pela propensão ao devir. Que propensão é essa? É aquela que não abre mão do intempestivo e que alerta o pesquisador sobre a emergência do qualitativo na cena investigativa e sobre o potencial de transgressão que se desdobra dessa emergência. 


\begin{abstract}
Reflexiones sobre una experiencia de investigación con la capoeira

Resumen: El objetivo de este artículo es describir los movimientos de una experiencia de investigación con la capoeira. Esta descripción pone en escena las desviaciones y las transgresiones que dan testimonio de cierta propensión al devenir del enfoque metodológico. Se busca trazar los modos en que los procedimientos se desconstruyen y se transforman en la investigación de campo. Tiene la intención de comprender cómo la intervención del investigador con el campo fuerza los principios reguladores de la acción a sus límites, manteniendo la actitud investigativa en tensión entre la función referencial que apunta a la aplicación regular de los procedimientos y la propensión a devenir. Así se evidencia la introducción de lo intensivo en las relaciones de investigación y es el registro de este intensivo que alimenta esta descripción.

Palabras clave: Métodos. Cartografía. Capoeira.
\end{abstract}

\begin{abstract}
Reflections about an investigation research experience with capoeira

Abstract: The aim of this article is to describe the movements of an investigation experience with capoeira. This description underscores deviations and transgressions that testify to some propensity towards the becoming of the methodological trajectory. We seek to map the ways in which the proceedings were deconstructed and transformed during field research. We intend to understand how researchers' involvement with fieldwork forces the regular principles of action to their limits, keeping the investigative attitude in the tension between the referential function - which points to regular application of proceedings - and the propensity towards becoming. The introduction of "the intensive" in the investigation relation is thus shown, and the record of that "intensive" nurtures this description.

Keywords: Methods. Cartography. Capoeira.
\end{abstract}

\title{
Referências
}

ALVAREZ, Jhonny Menezes. O aprendizado da capoeira angola como cultivo na e da tradição. Rio de Janeiro. 230 folhas. Tese (doutoramento) em Psicologia: Instituto de Psicologia - Universidade Federal do Rio de Janeiro, 2007.

ALVES, Flávio Soares. O corpo em movimento na Capoeira. São Paulo. 185 folhas. Tese (doutoramento) em Ciências: Escola de Educação Física e Esporte Universidade de São Paulo, 2011.

BARROS, Laura Pozzana de; KASTRUP, Virgínia. Cartografar é acompanhar

Movimento, Porto Alegre, v. 20, n. 3, p. 1111-1132, jul./set. de 2014. 
Reflexões sobre uma experiência investigativa ...

processos. In: PASSOS, Eduardo; KASTRUP, Virgínia; ESCÓSSIA, Líliana (Orgs.) Pistas do método da Cartografia: pesquisa-intervenção e produção de subjetividade. Porto Alegre: Sulina, 2009. p. 52-75.

DELEUZE, Gilles Diferença e Repetição. 2. ed. Rio de Janeiro: Graal, 2006.

DELEUZE, Gilles ; GUATTARI, Félix. Mil Platôs: capitalismo e esquizofrenia. São Paulo: Ed. 34, 1995a. v. 1.

DELEUZE, Gilles ; GUATTARI, Félix. Mil Platôs: capitalismo e esquizofrenia. São Paulo: Ed. 34, 1995b. v. 2.

GARCEZ, Pedro. A perspectiva da análise da conversa etnometodológica sobre o uso da linguagem em interação social. In: LODER, Letícia Ludwig; JUNG, Neiva Maria (Orgs.). Fala-em-interação social: introdução à análise da conversa etnometodológica. Campinas, SP: Mercado de Letras, 2008. p.17-38.

GOFFMAN, Erving. A situação negligenciada. In: RIBEIRO, Branca Telles; GARCEZ, Pedro (Orgs). Sociolinguística interacional. São Paulo: Loyola, 2002a. p.13-20.

GOFFMAN, Erving . Footing. In. RIBEIRO, Branca Telles; GARCEZ, Pedro (Orgs.) Sociolinguística Interacional. São Paulo: Loyola, 2002b. p.107-148.

GUATTARI, Felix A transversalidade. In: Psicanálise e transversalidade: ensaios de análise institucional. Aparecida, SP: Ideias e Letras, 2004. p.75-84.

KASTRUP, Virgínia. A aprendizagem da atenção na cognição inventiva. In: Psicologia \& Sociedade, Belo Horizonte, v.16, n.3, 2004. p.7-16.

KASTRUP, Virgínia ; TEDESCO, Silvia; PASSOS, Eduardo Políticas de cognição. Porto Alegre: Sulina, 2008.

KASTRUP, Virgínia; BENEVIDES DE BARROS, Regina Movimentos-funções do dispositivo na prática da cartografia. In: PASSOS, Eduardo; KASTRUP, Virgínia; ESCÓSSIA, Líliana (Orgs.). Pistas do método da Cartografia: pesquisaintervenção e produção de subjetividade. Porto Alegre: Sulina, 2009. p. 76-91.

ESCÓSSIA, Líliana; PASSOS, Eduardo (Orgs.). Cartografar é traçar um plano comum. In: Fractal; Revista de Psicologia, Niterói , v. 25, n. 2, p. 263-280, maio/ ago. 2013.

LABAN, Rudolf. Dança educativa moderna. São Paulo: Ícone, 1990.

LOURAU, René. Análise institucional práticas de pesquisa. Rio de Janeiro: UERJ, 1993.

LOURAU, René. A análise institucional. Petrópolis: Vozes, 1996.

LOURAU, René. L'écriture automatique: les Cahiers de l'implication. In: Revue d'analyse Institutionnelle, Saint-Denis, n. 2, p.35-38, 1998.

Movimento, Porto Alegre, v. 20, n. 3, p. 1111-1132, jul./set. de 2014. 
NIETZSCHE, Friedrich. A vontade de poder. Rio de Janeiro: Contraponto, 2008.

PASSOS, Eduardo; KASTRUP, Virgínia; ESCÓSSIA, Líliana (Orgs.) Pistas do método da Cartografia: pesquisa-intervenção e produção de subjetividade. Porto Alegre: Sulina, 2009.

SOUZA, Pedro. O sujeito fora de si: movimentos hídridos de subjetivação na escrita foucaultiana. In: RAGO, Margareth; VEIGA-NETO, Alfredo (Org.) Figuras de Foucault. Belo Horizonte: Autêntica, 2008. p.205-214.

TEDESCO, Silvia Helena; SADE, Christian; CALIMAN, Luciana Vieira. A entrevista na pesquisa cartográfica. In: Fractal : Revista de Psicologia, Niterói, v. 25, n. 2 , p. 299-322, maio/ago, 2013.

Endereço para correspondência:

Departamento de Educação Física - IB - Universidade Estadual Paulista - Campus de Rio Claro

Endereço: Avenida 24 A, 1515.

CEP: $13506-900$

Rio Claro - SP.

Recebido em: 19.08.2013

Aprovado em: 29.04.2014 